Objectives: To compare the clinical evolution of patients with axial SpA (axSpA) and peripheral SpA (pSpA) included in this program.

Methods: Patients from the Esperanza cohort fulfilling ASAS criteria for axSpA or pSpA and completed the 6-year follow-up were included. Patients were classified according to the predominant symptom. In case of having axSpA and pSpA, they were classified as axSpA. Clinical features, disease activity and treatment aspects at baseline and 6-year visit were evaluated.

Results: From 775 patients recruited at baseline, 6-year follow-up data from 178 (83.5\%) fulfilling ASAS criteria at the final visit were available: $133(74.7 \%)$ for axSpA and 45 for pSpA (25.3\%). 118 (66.3\%) were males (50.6\% with axSpA and $62.2 \%, p S p A, p=0.4)$. Patients with axSpA had more frequently positive HLA-B27 $(90.5 \%)$ vs. (9.5\%), $p<0.001$. Follow-up clinical features are shown in Table 1. At the final visit, both axSpA and $p S p A$ presented an improvement in clinical symptoms, disease activity (CRP, BASDAI, ASDAS and VAS-pt) and quality of life (ASQoL). A worsening of mobility (BASMI) was observed in both groups. The prevalence of uveitis, psoriasis and inflammatory bowel disease (IBD) at baseline was $10.7 \%, 18 \%$ and $5.6 \%$, respectively. At the 6 -year visit, the cumulative prevalence (CP) was $14 \%$ for uveitis $(16.5 \%$ in axSpA and $6.7 \%$ in pSpA), $22.5 \%$ for psoriasis (12.8\% in axSpA and $51.1 \%$ in pSpA) and $7.9 \%$ for IBD $(5.3 \%$ in axSpA and $15.6 \%$ in pSpA). Most of the patients were prescribed NSAIDS at baseline and more patients maintained this treatment at the 6-year visit in axSpA compared with $\mathrm{pSpA}(96.9 \%$ vs $87.5 \%, \mathrm{p}=0.02)$. At the final visit, a higher percentage with $\mathrm{pSpA}$ received csDMARDs in comparison with axSpA $(81 \%$ vs. $35.7 \%$, p<0.001). Sixty $(44.4 \%)$ patients received biologic therapy at the final visit and no differences were observed in their prescription: $43 \%$ in axSpA and $48.6 \%$ in $\operatorname{psp} A(p=0.6)$.

Conclusion: The early diagnosis of recent-onset $\mathrm{SpA}$ achieves a significant improvement in clinical features, disease activity and quality of life in patients with axSpA and pSpA after 6 years of follow-up. Although previous publications revealed a low radiographic progression in this cohort ${ }^{1}$, the worsening of BASMI must aware clinicians of possible evolutive structural damage.

REFERENCE:

[1] Fernández-Carballido et al. RMD Open. 2020 Sep;6(2):e001345

able 1. Follow-up clinical features at baseline and 6-year visit in patients with axSpA and pSpA.

\begin{tabular}{|c|c|c|c|c|c|c|c|c|}
\hline & \multicolumn{2}{|c|}{ Baseline visit } & \multicolumn{3}{|c|}{ Six-year visit } & \multirow[b]{2}{*}{$\begin{array}{c}P \\
\text { value } \\
3-4\end{array}$} & \multirow[b]{2}{*}{$\underset{\substack{P \\
\text { value } \\
1-3}}{P}$} & \multirow[b]{2}{*}{$\begin{array}{c}P \\
\text { value } \\
2-4\end{array}$} \\
\hline & $\begin{array}{c}1 \\
\underset{\mathrm{AxSpA}}{\mathrm{n}=133}\end{array}$ & $\underset{\substack{\mathrm{pSpA} \\
\mathrm{n}=45}}{2}$ & $\underset{\substack{P \\
\text { value } \\
1-2}}{c}$ & $\underset{\substack{A x S p A \\
n=133}}{3}$ & $\begin{array}{c}4 \\
\mathrm{pSpA} \\
\mathrm{n}=45\end{array}$ & & & \\
\hline Age (years), mean $\pm \mathrm{SD}$ & $33.2 \pm 7.5$ & $35.3 \pm 7$ & 0.09 & $39.6 \pm 9.6$ & $40.9 \pm 6.9$ & 0.107 & $<0.001$ & $<0.001$ \\
\hline Back pain, n (\%) & $125(94 \%)$ & $21(46.7 \%)$ & $<0.001$ & $40(30 \%)$ & $6(13.3 \%)$ & 0.083 & $<0.001$ & 0.002 \\
\hline Arthritis, $\mathrm{n}(\%)$ & $32(24.1 \%)$ & $40(89 \%)$ & $<0.001$ & $8(6 \%)$ & $10(22.2 \%)$ & 0.006 & $<0.001$ & 0.061 \\
\hline Enthesitis, $n(\%)$ & $46(34.6 \%)$ & $23(51.1 \%)$ & 0.11 & $10(7.5 \%)$ & $1(2.2 \%)$ & 0.39 & $<0.001$ & $<0.001$ \\
\hline Dactylitis, $\mathrm{n}(\%)$ & $13(9.8 \%)$ & $15(33.3 \%)$ & 0.01 & $1(0.8 \%)$ & $2(4.4 \%)$ & 0.24 & $<0.001$ & $<0.001$ \\
\hline CP uveitis, $n$ (\%) & $17(12.8 \%)$ & $2(4.4 \%)$ & 0.28 & $22(16.5 \%)$ & $3(6.7 \%)$ & 0.5 & $<0.001$ & $<0.001$ \\
\hline CP Psoriasis, n (\%) & $11(8.3 \%)$ & $21(46.7 \%)$ & $<0.001$ & $17(12.8 \%)$ & $23(51.1 \%)$ & 0.02 & $<0.001$ & $<0.001$ \\
\hline CP IBD, n (\%) & $4(3 \%)$ & $6(13,3 \%)$ & 0,029 & $7(5.3 \%)$ & $7(15.6 \%)$ & 0,69 & $<0.001$ & $<0.001$ \\
\hline $\operatorname{SJC}(0-68)$, mean \pm SD & $0.2 \pm 0.9$ & $2.1 \pm 2.8$ & $<0,001$ & $0.2 \pm 1.1$ & $0.5 \pm 1.1$ & 0.11 & 0.62 & $<0.001$ \\
\hline $\mathrm{CRP}(\mathrm{m} g / \mathrm{L})$, mean $\pm \mathrm{SD}$ & $8.3 \pm 11.6$ & $8.9 \pm 12.7$ & 0.77 & $3.6 \pm 4.9$ & $5.1 \pm 7.7$ & 0.26 & $<0.001$ & 0.045 \\
\hline $\operatorname{BASDAI}(0-10)$, mean \pm SD & $4 \pm 2.2$ & $4.2 \pm 2.4$ & 0.59 & $2.4 \pm 2.1$ & $2.3 \pm 2.1$ & 0.67 & $<0.001$ & 0.001 \\
\hline $\operatorname{BASFI}(0-10)$, mean \pm SD & $2.4 \pm 2.2$ & $2.4 \pm 2.4$ & 0.94 & $2.1 \pm 2.2$ & $1.6 \pm 1.9$ & 0.2 & 0.17 & 0.289 \\
\hline BASDAS, mean \pm SD & $2.3 \pm 1.1$ & $2.5 \pm 1.3$ & 0.264 & $1.6 \pm 1.4$ & $1.6 \pm 0.9$ & 0.690 & $<0.001$ & 0.001 \\
\hline BASMI, mean \pm SD & $1.4 \pm 1.3$ & $1.2 \pm 0.9$ & 0.43 & $1.9 \pm 1$ & $1.6 \pm 0.7$ & 0.19 & $<0.001$ & 0.002 \\
\hline VAS $(0-10)$ physician, mean \pm SD & $3.1 \pm 2.4$ & $2.9 \pm 2.4$ & 0.61 & $1.8 \pm 1.8$ & $1.8 \pm 1.6$ & 0.92 & $<0.001$ & 0.04 \\
\hline VAS $(0-10)$ patient, mean $\pm S D$ & $4.1 \pm 2.7$ & $4.8 \pm 3$ & 0.23 & $2.8 \pm 2.3$ & $2.4 \pm 2.2$ & 0.32 & $<0.001$ & 0.03 \\
\hline ASQoL, mean \pm SD & $5.9 \pm 4.7$ & $6.4 \pm 5.6$ & 0.6 & $2.9 \pm 3.8$ & $3.9 \pm 4.9$ & 0.38 & $<0.001$ & 0.008 \\
\hline
\end{tabular}

Data are expressed as mean \pm standard deviation (SD) for cuantitative variables and number (percentage) for cualitative variables. Abbreviations: AxSpA, axial spondyloarthritis. PspA, peripher sondyloarthritis. SD, (standard deviation). Impr, improvement. CP, cumulative prevalence. IBD: Inflammatory Bowel Disease. CRP: C-Rective Protein SJC: Swollen Joint Count VAS: Vis: An ASQD Ankylosing Spondylis quality of life. BA

BASDAL-based ASDAS, similar to the ASDAS-CRP but uses only the BASDAI ond CRP.

Acknowledgements: The Spanish Foundation of Rheumatology received funding from Pfizer (formerly Wyeth) to develop the Esperanza Program. Later, the Program has been supported by restricted grants from the Instituto de Salud Carlos III and Fondos FEDER (FIS PI13/02034 and PI17/01840) and AbbVie.

Disclosure of Interests: Carolina Tornero: None declared, Victoria Navarro-Compán: None declared, Beatriz Joven-lbáñez: None declared, RAQUEL ALMODOVAR: None declared, Xavier Juanola-Roura: None declared, Cristina Fernández-Carballido: None declared, Juan Carlos Quevedo-Abeledo: None declared, Jose Rosas: None declared, Azucena Hernández: None declared, Carlos A. Montilla-Morales: None declared, Jose Ramón Maneiro: None declared, A. Juan-Mas: None declared, Jose Antonio Pinto Tasende: None declared, Mireia
Moreno: None declared, Jesus Sanz: None declared, Teresa Ruiz Jimeno: None declared, Manuel Moreno: None declared, María Lourdes Ladehesa Pineda: None declared, Eugenio de Miguel Speakers bureau: AbbVie, Novartis, Pfizer MSD, BMS, UCB, Roche, Grunental, Janssen, Sanofi., Paid instructor for: Janssen, Novartis, Roche, Consultant of: AbbVie, Novartis, Pfizer, Galapagos, Grant/ research support from: Abbvie, Novartis, Pfizer.

DOI: 10.1136/annrheumdis-2021-eular.2725

\section{POS0997 PERFORMANCE OF ASDAS VERSUS BASDAI DURING PREGNANCY}

P. Fischer ${ }^{1}$, A. Zbinden ${ }^{1}$, F. Foerger ${ }^{1} .{ }^{1}$ University Hospital and University of Bern, Rheumatology and Immunology, Bern, Switzerland

Background: Disease activity in patients with axial spondyloarthritis (axSpA) can be measured by BASDAI and ASDAS. Both instruments were validated in non-pregnant patients with cutoff values for active diseases. In pregnant women with axSpA, however, BASDAI and ASDAS scores might be biased by signs and symptoms of pregnancy itself.

Objectives: To compare the performance of ASDAS and BASDAI during pregnancy

Methods: Patients with axSpA were prospectively followed before pregnancy, at each trimester and 6 to 12 weeks postpartum. Disease activity was assessed by BASDAI, ASDAS, patient global assessment (PGA) and physician global assessment (PhGA). We analysed the disease course throughout pregnancy and postpartum, the correlation between BASDAI and ASDAS and the agreement in the classification of active disease. We applied receiver operating curves (ROC) to evaluate the cut-off points in pregnant patients.

Results: The study involved 40 women with axSpA. Disease activity scores were higher during pregnancy (median ASDAS score: 2.5, median BASDAI score 3.1) than during a non-pregnant state (median ASDAS score 2.3, median BASDA score 2.1). Median BASDAl scores were highest at the first trimester, median ASDAS scores were highest at the second trimester. ASDAS strongly correlated with BASDAI, both in the pregnant and in the non-pregnant state $(r=0.796$, $r=0.727$ ). However, there was a discordance when analysing the proportion of patients with high disease activity using the common cut-off values (ASDAS $>2.1$, BASDAS $>4)$. More patients had high disease activity when measured by ASDAS ( $1^{\text {st }}$ trimester $\left.(\mathrm{T}): 63 \%, 2^{\text {nd }} \mathrm{T}: 76 \%, 3^{\text {rd }} \mathrm{T}: 61 \%\right)$ compared to those measured by BASDAI ( $\left.1^{\text {st }} \mathrm{T} 43 \%, 2^{\text {nd }} \mathrm{T}: 39 \%, 3^{\text {rd }} \mathrm{T}: 34 \%\right)$. The $\kappa$ coefficient showed only fair agreement $(\kappa=0.39)$. ROC analysis among pregnant patients showed that the cut-off point estimation for high disease activity using ASDAS $>2.75$ corresponded to a BASDAI $>4$. The ASDAS $>2.75$ cut-off for high disease activity had a good agreement with BASDAI $>4(\kappa=0.657)$. When ASDAS $>2.75$ was applied in pregnant women with axSpA, about $40 \%$ experienced high disease activity.

Conclusion: During pregnancy, the majority of women with axSpA experience ongoing disease activity. However, the cut-off values defining low and high disease activity might differ between pregnant and non-pregnant individuals since BASDAI and ASDAS are biased by pregnancy related symptoms like fatigue and mechanical back pain.

Disclosure of Interests: None declared.

DOI: 10.1136/annrheumdis-2021-eular.2859

\section{POS0998 SPONDYLOARTHRITIS AND SLEEP DISORDERS}

S. Lahrichi ${ }^{1}$, K. Nassar ${ }^{1}$, S. Janani ${ }^{1} .{ }^{1}$ University Hospital of IBN ROCHD, Rheumatology, Casablanca, Morocco

Background: Spondyloarthropathies (SpA) are a group of chronic and progressive diseases, characterized in particular by a progressive stiffening of the spine, spreading to neighboring joints or to certain tissues, which could lead in the long term to progressive stiffening and functional impairment. This conditioncancauseinsomnia problems and impaired sleep quality.

Objectives: To assess the impact of $\mathrm{SpA}$ on the quality of sleep.

Methods: This is a retrospective study over a period of 4 years from January 2015 to December 2019, including all the medical records of patients with SpA followed in the Department of Rheumatology of the University Hospital of Ibn Rochd, Casablanca. We evaluated for each patient two validated scores: the Epworth somnolence scale rated from 0 to 24, and the Pittsburgh sleep score rated from 0 to 21 with 7 components. Patients with a psychiatric history or who were followed up for neurological pathologies were excluded.

Results: 178 patients were included. $60.67 \%$ were men with an average age of 36.32 years ( $14-68$ years). $45.01 \%$ had axial $\mathrm{SpA}, 29.77 \%$ had psoriatic arthritis, and $25.22 \%$ were followed for SpA associated with inflammatory bowel disease. $45 \%$ had associated comorbidities: there were 18 diabetics and 34 hypertensive, $16.58 \%$ were smokers. Clinically, $85.42 \%$ presented a back pain initially on examination, $55 \%$ presented a polyarthralgia, and $39.88 \%$ an oligoarthritis. $63 \%$ had radiological sacroiliitis, and $35.14 \%$ had bilateral coxitis. $13.48 \%$ had a positive HLA B27 and $58.89 \%$ had 
positive inflammatory assessment with very high activity indices, with a mean of 4.6. $64.66 \%$ of the patients received NSAIDs, of which $11 \%$ responded well. $57 \%$ were treated with csDMARDs, and $17.86 \%$ were treated with biologics. At the time of our study, the mean visual analog scale was $5.84 \pm 1.7$ out of $10(2-9)$. The mean Epworth score was $8.38 \pm 5.2(0-21) .56 .1 \%$ of patients had no sleep debt, $33.3 \%$ had a sleep deficit, and only $10.6 \%$ had signs of drowsiness. For the overall Pittsburgh score, the mean was $7.02 \pm 3.6(1-18)$. The mean of "subjective quality of sleep" was 1.12 , "sleep latency" was 1.22, "duration of sleep" was 1.06, "usual sleep efficiency" was 0.74 , "Sleep disturbance" of 1.28 , "use of a sleep medication" of 0.54 , and the average of the component concerning "poor shape during the day" was 1.03 out of 3 . The LEQUESNE index went from an average of 6 to 8 , which corresponds to an average handicap $(P=0.2)$ over a period of 3 years. $68 \%$ of the patients had an alteration in the quality of sleep, starting on average three years after the onset of symptoms. $11 \%$ reported having experiencedanxiety and depressive symptoms, and reported having used antidepressants or anxiolytics in the past 5 years.

Conclusion: Our study showed the negative impact of SpA on the duration and overall quality of sleep. The degree of pain as well as functional impairment can cause and worsen sleep disturbances in SpA. We have shown that the Pittsburg score increases significantly with the increase of pain. The Lequesne score and that the Epworth score increase with disease activity[1].

REFERENCES:

[1] StolwijkC,vanTubergenA,Castillo-OrtizJD,BoonenA.Prevalenceofextra-articularmanifestationsinpatientswithankylosingspondylitis:asystematicreviewandmeta-analysis.AnnRheumDis2015;74:65-73.

Disclosure of Interests: None declared.

DOI: 10.1136/annrheumdis-2021-eular.2909

\section{POS0999 HIGH CORRELATIONS BETWEEN QUESTION 1 \& 2 OF THE BASFI: AN OPPORTUNITY TO STREAMLINE THE BASFI}

M. Maclean ${ }^{1}$, S. Maguire ${ }^{1}$, F. B. O'shea'. ' St. James' Hospital, Rheumatology, Dublin, Ireland

Background: The Bath Ankylosing Spondylitis Functional Index (BASFI) is a useful tool to quantitatively characterise functional ability in a patient with axial spondyloarthropathy (axSpA). Whether first presentation, decompensated, or routine follow-up, BASFI can help establish a more accurate understanding of disease progression, or response. As with any questionnaire, relevance and absence of redundancy is required. This analysis questions the redundancy of the first two questions of the BASFI:

1) How difficult is it to put socks on your feet?

2) How difficult is it to pick a pen up off the floor?

Objectives: To compare variation in reporting of questions one and two of the BASFI, to establish redundancy or exclusivity of these questions.

Methods: IBM SPSS version 26 was used for data analysis. Data from axSpA patients who attended the Rheumatology department during the study period were included in the analysis where BASFI scores were available. Both variables (pen scores and sock scores) were assessed with a Shapiro-Wilk's test for normal distribution. The variables were also assessed for the presence of a monotonic relationship by visual inspection of a scatterplot of the variables. Once a monotonic relationship was established a Spearman's rank order correlation between the sock score and pen scores for each participant was analysed.

Results: In total data from 82 axSpA patients were included in this analysis. Population was made up of $28 \%$ (23) females, $72 \%$ (59) males with mean BASDAI score 4.33 and mean BASFI score 3.88 (Table 1). Both variables were not normally distributed as assessed by Shapiro-Wilk's test $(p<0.05)$ necessitating a Spearman's rank-order correlation for analysis. Preliminary analysis variables demonstrated the relationship between the variables to be monotonic as determined by visual inspection of the scatterplot (graph 1) with no outliers detected. There was a statistically significant, strong positive correlation between sock scores and pen scores in this axSpA population, $r_{\text {partial }}(80)=0.809$ significant at the $p<0.01$ level.

Table 1. Descriptive output of data

\begin{tabular}{ll}
\hline & $\%(\mathbf{n})$ \\
\hline $\mathbf{n}$ & 82 \\
Females & $28 \%(23)$ \\
Males & $72 \%(59)$ \\
Age & 45.03 \\
BASDAI & 4.33 \\
BASFI & 3.88 \\
Pen score & 3.93 \\
Sock score & 2.88 \\
Sock score greater & $7.3 \%(6)$ \\
Pen score greater & $50 \%(41)$ \\
Same scores & $42.7 \%(35)$ \\
\hline
\end{tabular}

Conclusion: There is a strong positive correlation between sock (question 1) and pen scores (question 2) as captured by the BASFI. It appears that both questions are capturing a similar functional limitation in patients with axSpA. In order to minimise redundancy and improve the relevance of the BASFI our results support the removal of one of these questions to simplify the BASFI. From a practical perspective, putting on socks (question 1) would be a more commonly encountered daily activity than picking up a

pen from the floor(question 2). As such, we would suggest removal of question 2 from the BASFI.

Table 1 \& Figure 1

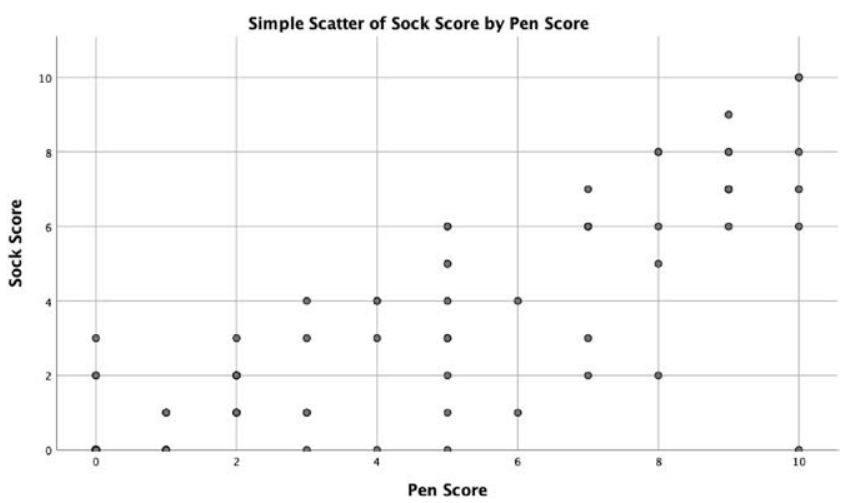

Graph 1. Spread of Data points demonstrating a monotonic relationship with no outliers

Disclosure of Interests: Michael MacLean: None declared, Sinead Maguire Grant/research support from: Recipient of the Gilead Inflammation Fellowship, Finbar Barry O'Shea: None declared.

DOI: 10.1136/annrheumdis-2021-eular.2913

\section{\begin{tabular}{|l|l}
\hline POS1000 COMORBIDITIES ASSOCIATED TO \\
\hline
\end{tabular} SPONDYLOARTHRITIS}

S. Bouden ${ }^{1}$, L. Kharrat ${ }^{1}$, A. Ben Tekaya ${ }^{1}$, O. Saidane ${ }^{1}$, R. Tekaya ${ }^{1}$, I. Mahmoud ${ }^{1}$, L. Abdelmoula'. ' Hospital Charles Nicolle, Rheumatology, Tunis, Tunisia

Background: In contrast to other chronic rheumatic diseases such as rheumatoid arthritis, comorbidities associated to spondyloarthritis (SpA) and their impact on disease outcomes are less well studied.

Objectives: The aim of our study was to investigate the prevalence of comorbidities among SpA patients and to determine factors influencing their appearance. Methods: We conducted a retrospective study including patients meeting the Assessment of SpondyloArthritis International Society (ASAS) criteria between 2000 and 2020.

The following comorbidities were collected: cardiovascular pathologies and their risk factors (smoking, arterial hypertension, diabetes, dyslipidemia and obesity), neoplasms, osteoporosis, depression, infections, gastrointestinal and pulmonary disorders. Results: We included 138 patients. Sixty-eight per cent of them were males. The mean age was $45.73 \pm 12.66$ years. The mean age at the disease onset was $28.89 \pm 12.54$ years. The mean CRP was $33.38 \pm 39.65 \mathrm{mg} / \mathrm{dL}$. The mean BASDAI and ASDAS-CRP were $4.21 \pm 2.23$ and $3.06 \pm 1.26$, respectively. The mean BASFI was $4.77 \pm 2.58$.

Sixty patients had at least one comorbidity (43.5\%): 53 patients had one comorbidity (38.4\%), 21 accumulated two types of comorbidities (15.2\%) and 7 patients accumulated three types or more (5\%).

Osteoporosis was the most frequent comorbidity, it was present in $23.1 \%$ of the cases $(n=32)$, followed by tuberculosis $8.7 \%(n=12)$, stomach ulcers $5.1 \%(n=7)$, pulmonary superinfection $2.9 \%(n=4)$, neoplasia $2.2 \%(n=3)$ and then depression $1.4 \%(n=2)$.

Cardiovascular risk factors were noted in 44 patients $(31.9 \%)$ : hypertension $(15.9 \%)$, diabetes $(12.3 \%)$, dyslipidemia $(9.4 \%)$ and obesity $(8.7 \%)$.

Thirty-seven per cent of our patients were smokers.

$\mathrm{SpA}$ patients with comorbidities were significantly older than those without $(50.2 \pm 11.07$ versus $42.3 \pm 12.8$ years, $p<0.0001)$.

The presence of comorbidities was significantly associated to a higher disease activity evaluated by BASDAI $(p=0.005)$ and ASDAS-CRP $(p=0.002)$. Furthermore, BASFI was significantly higher among patients with comorbidities (5.47 \pm 2.38 versus $4.31 \pm 2.62, p=0.028)$.

However, no association was found between presence of comorbidities and smocking or CRP.

Conclusion: Our results show that more than $40 \%$ of our SpA patients presented with at least one comorbidity. Remarkably, the presence of comorbidities 